\title{
Rewarding Participation in Youth Sport: Beyond Trophies for Winning
}

\section{Premiando la participación en el deporte para jóvenes: más allá de los trofeos por ganar}

\section{Colleen English}

Penn State Berks. Kinesiology Department

\author{
CORRESPONDENCIA:
}

Colleen English

\begin{abstract}
Recently, many parents, sportswriters, and social critics have expressed concern for young athletes being given participation trophies. They claim that it fosters a sense of entitlement and teaches youngsters that they do not need to earn rewards. I argue that youth sport participants should not be rewarded only for participation, but that they should be given opportunities for earing awards beyond mere victory. This is because a variety of values, such as symbolic meaning, challenge and risk, aesthetics, and high-quality relationships with teammates and opponents, deserve reward as well. I conclude that coaches and organizers should find ways to given tokens to most youth sport participants for achieving, or striving to achieve, these alternate values.
\end{abstract}

Key words: youth sport, values, competition.

\section{Resumen}

Recientemente, padres, escritores deportivos y críticos sociales han expresado su preocupación porque se entreguen trofeos de participación a jóvenes atletas. Ellos afirman que esto fomenta la sensación de permisividad y enseña a los jóvenes que no necesitan ganar recompensas. Yo defiendo que los participantes en deporte para jóvenes no deberían ser premiados sólo por participar, pero se les deberían ofrecer más oportunidades para conseguir premios que van más allá de la victoria. Esto es porque una diversidad de valores, como el significado simbólico, el desafío y riesgo, la estética, y las relaciones de calidad entre compañeros también merecen ser premiados.

Concluyo que los entrenadores y organizadores deberían encontrar caminos para premiar a los participantes más jóvenes por conseguir, o esforzarse por conseguir, estos valores alternativos.

Palabras clave: deporte para jóvenes, valores, competición. 
In August 2015, professional American football player James Harrison posted a photograph of his children's large participation trophies from their youth sports league. He captioned this photo with the following:

"I came home to find out that my boys received two trophies for nothing, participation trophies! While I am very proud of my boys for everything they do and will encourage them till the day I die, these trophies will be given back until they EARN a real trophy. I'm sorry I'm not sorry for believing that everything in life should be earned and I'm not about to raise two boys to be men by making them believe that they are entitled to something just because they tried their best...cause sometimes your best is not enough, and that should drive you to want to do better...not cry and whine until somebody gives you something to shut u up and keep you happy" (quoted in Dator, 2015).

He followed his caption by tagging it "\#harrisonfamilyvalues."

Harrison makes a few key points in his comment. First, he notes that these tokens rewarded his children for nothing (unlike trophies for winning, which Harrison infers are both acceptable and preferable), implying that mere participation in sport is not worthy of awards. Secondly, he clearly views youth athletics as a valuable teaching ground for building character-a place for youngsters to learn the value of hard work and the often difficult truth that even their best efforts may not yield trophies or tangible rewards.

Harrison's post received nearly 20,000 "likes" on Instagram while almost 4,000 people commented on his photo and caption. Many of these comments supported Harrison's cause, ranging from "Completely agree" and "We need more thinking like this" to "I'm going to raise my kids like this" and "Your sons are lucky to have you." ESPN noted that at least one fan shouted to Harrison after a game, "I appreciate what you're teaching your sons." Few media outlets or fans begrudged Harrison his position and many even used it to decry the entitlement of today's youth.

Upon first reading this I admit my immediate reaction was one of agreement. Trying to win and being rewarded for victory are not inherently problematic. Competition, including the declaration of winners, is an important element of sport that should not be totally excluded from youth athletics (Torres \& Hager, 2007). Young athletes must learn that merely showing up is not worthy of reward, both in the larger world of sport or within wider society. Concerns about entitlement are compelling. Social critics provide reasonable arguments that giving participation trophies to young athletes will teach them that everyone deserves the same token of achievement, no matter how well they performed. Following this line of reasoning, this sentiment may lead to unreasonable expectations in school, careers, and the rest of adulthood. SBNation's Dani Bostick put it clearly: "Entitlement is a societal scourge, and it is important for kids to understand that both achievement and effort are essential ingredients for success. It is unrealistic and dangerous to teach kids overtly or inadvertently that jobs, money, healthy relationships, and opportunities magically appear like participation ribbons at the end of a Kindergarten fun run" (Bostick, 2015).

Despite these generally persuasive arguments against distributing participation trophies to youngsters, upon further reflection, I questioned: Are participation trophies really that bad? Do young athletes only deserve tokens of achievement if they have been victorious?

An excessive focus on competition can be harmful to athletes. By emphasizing hypercompetitive, win-atall costs attitudes, organizations and coaches weaken other values. When young athletes are only rewarded for winning, they receive the message that the only and most worthwhile value of sport is victory. All other values, such as meaning, aesthetics, and interpersonal relationships are secondary and underemphasized. I will argue that youth sport participants can and should be rewarded for more than just winning. Though I will not advocate for distributing trophies to young athletes for merely "showing up," I will contend that tokens of achievement can be given for meeting, or striving to meet, a variety of alternate sport values, such as symbolic meaning, challenge, aesthetics, and teamwork ${ }^{1}$. The purpose of these tokens is to provide motivation to participate in the sport and they may be given periodically, rather than exclusively at the end of the season. To carry out this argument I will first discuss the purpose of youth sport. Secondly, I will provide an argument for alternate values in athletics, including finding personal meaning through symbolism, challenge, risk, and aesthetics and building strong interpersonal relationships. Finally, I will conclude with suggestions for rewarding youth athletes.

\footnotetext{
1 Throughout this essay, I will use the terms trophy, reward, and token interchangeably to refer to rewards earned by meeting or striving to meet alternate sport values. These tokens are different from trophies earned for contesting victory.
} 


\section{Purpose of youth sport}

Unlike elite, adult sport, youth athletics tend to explicitly espouse values beyond winning. They often tie together a variety of educational experiences, including the development of sport skills, leadership, and teamwork. The National Alliance for Youth Sport (NAYS) advocates for positive, healthy, and fun physical activity experiences for young people ${ }^{2}$. Their national standards aim to create "childcentered" policies and philosophies that "ensure positive benefits of participation" by suggesting standards and practices related to skill development, competition, tournament play, and coaching (National Alliance for Youth Sports, 2017). In general, NAYS's recommendations focus on developing fundamental skills while placing little emphasis on scores, standings, and competitive play.

Sport-specific youth organizations also put in place policies that emphasize positive experiences for participants. Little League Baseball, according to their mission, "assists youth in developing the qualities of citizenship, discipline, teamwork, and physical wellbeing." Their website goes on to say that the "program is designed to develop superior citizens rather than stellar athletes" ("Why We Are Relevant," n.d.). The American Youth Soccer Organization (AYSO) proposes a similar mission as Little League. AYSO purports to promote a "fun, family environment" based on six philosophies, including "everyone plays, balanced teams, open registration, positive coaching, good sportsmanship, and player development"("Mission \& Vision," n.d.). The mission of Pop Warner, a group that organizes youth American football, includes "instill[ing] life-long values of teamwork, dedication, and a superior work ethic in the classroom and on the playing field" as part of their mission. Pop Warner also ensures that everyone participates and does not conduct try-outs or allow the cutting of rosters ("About Pop Warner Youth Football, Cheer \& Dance," n.d.). At least in their words, these groups advocate for the promotion of well-rounded athletes, including both skill development and other character traits, such as sportsmanship, teamwork, and dedication as key elements of their mission. Furthermore, these organizations do not center on victory and seem to encourage coaches to keep their young players focused on learning rather than winning.

2 Although youth sport guidelines and policies may differ by country, I have chosen to focus on youth sport organizations in the United States for simplicity. Additionally, I focus my argument on youth who have not yet entered secondary schooling (approximately 12 years of age), the age of which (in the United States) begins varsity sports.
Although it seems that, at least on the surface, many youth sport associations eschew competition, some sport philosophers identify competition, including attempting to attain victory, as a positive sport value, even for children. Torres and Hager (2007) argue that the trend of youth organizations excessively de-emphasizing or eliminating competition is "unwarranted and misleading for children" (p. 194). Rather than eliminate the "central purpose" of competitive sport, youth athletics should aspire to teach children to "compete in a good and decent manner" (p. 207). While Torres and Hager do not recommend win-at-all-costs forms of competition, they do contend that viewing sport from a mutualist point of view, where both winner and loser can find value in competition, supports keeping competitive elements as part of sport for children. Young people can experience good sport while also striving to achieve victory.

My argument falls in line with both the perspectives of youth sport organizations on emphasizing a variety of values in sport and with Torres and Hager's contention that competition should remain a part of youth athletics. Good sport entails skills unique to testing and contesting, where testing provides foundational challenges and contesting allows players to demonstrate their skills in relation to one another (Kretchmar, 1975a). Demonstrating excellence in both of these domains proves to be a primary value in sport. Thus, young sport participants must be exposed to competition and taught the value of it. It may follow, then, that awarding trophies or other tokens to winners might be one way to demonstrate that testing and contesting excellence is important.

However, it does not follow that competition is the only worthwhile aspect of youth sport. As organizations like NAYS, AYSO, Little League Baseball, and Pop Warner demonstrate, other values also lie at the heart of sport. Meaningful play, teamwork, leadership, and respect for opponents all can and should be a part of a sporting experience. Rewarding accomplishment in these areas can demonstrate that these are meaningful values.

Additionally, it expands what Harrison, numerous parents, and sportswriters mean when they say they want children to "earn" their trophies. While rewarding alternate values in sport might mean that young athletes receive tokens even if they do not win, these awards are still earned. In the following section, I will argue why alternate values, such as meaning and relationships with others are important to athletic experiences. 


\section{Alternate sources of meaning in sport}

While competitive outcomes provide a great deal of meaning for some participants, other sources of meaning are available to athletes. Winning does not have to be the primary or sole priority for young sportspeople. Instead, they may focus on a variety of other potential sites for meaning. I will focus on three potential sources: (1) symbolism; (2) challenge and risk; and (3) aesthetic value.

\section{Meaning through symbolism}

One way that meaning arises in sport is through its ability to tell us about ourselves and to tell us about the world around us. For Metheny (1965), meaningful movement is a profoundly human experience, as she argues, "The wonder of being human is that we have the ability to make motions that do matter to us as human beings" (Metheny, 1965, p. 106, emphasis original). Athletics and other forms of physical movement have the potential to create and explain the meanings of our actions and foster a unique understanding of the world around us.

These movements can be meaningful in two sensesboth as denotations and connotations. Denotation "is the power to name" while connotation indicates motivation and emotional mood, eliciting powerful symbolism (Metheny, 1965, pp. 74, 174). Sport is ripe with symbolic potential-for indications of hope, tragedy, limitation, power, grace, serendipity, and so much more. This symbolism is not necessarily tied to winning, though competitive success and failure carry considerable potential for symbolic understanding. Symbolic meaning in movement offers value for participating in sport by helping athletes gain a richer and fuller picture of themselves as embodied beings, of the world as a place in which to move skillfully, and of relationships between themselves and their surroundings.

As noted above, the sort of meaning found in sport is virtually limitless. Not only can it provide a way for sportspeople to learn more about the world and its characteristics, but sport can be symbolic of personal narratives. In a McIntyrean sense, we learn of ourselves in the roles we play and the coherent narratives that are shaped by those roles (MacIntyre, 1984). A young athlete might identify as a brother, son, student, and soccer player. Or, as a daughter, sister, friend, and basketball player. This self-identification conveys important personal characteristics and values. If youth sports can focus on developing this personal meaning, rather than serving merely as a place to collect victories, then sport and its associated symbolism can become accessible and valuable to more children. This symbolism adds unique value to sport, allowing athletes to enhance their self-identity and enrich personal meaning.

Athletics can also inform our personal histories. For some, sport symbolizes bonds with others, an escape from suffering, or a place to find success. Sportswriter Rick Reilly, for example, in recalling his childhood with an alcoholic father, acknowledges that he was "raised by sports" (Reilly, 2014, para. 9). Other athletes may see sport as symbolizing an escape from hardship, literally and figuratively. Arkansas State hurdler Sharika Nelvis, discovered track and field as a way to provide opportunity and relief from lifelong struggle and instability (such as losing both of her parents by age seven). With track and field, she "found a place that felt like home should be" (Jennings, 2014, para. 28). For both Reilly and Nelvis, sport took on meaning within their own personal histories.

Meaning and symbolism in sport give it greater depth. Athletics does not only denote specific knowledge (i.e. "She made a jump shot") but also serves to connote emotions, convey meaning, generate personal narratives, and develop personal histories. These powerful meanings help us communicate and remind us of our own stories. Because of this, symbolism and meaning provide alternate values in sporting competitions.

\section{Meaning through challenge and risk}

In addition to providing symbolic meaning, sport, by providing specific challenges, can help athletes develop a better sense of self and human possibility. Following transcendental philosophers, such as Thoreau, Anderson sees sport as an activity that can create a good life by opening "transformative possibilities," such as power, freedom, peace, and beauty-"traits of a life worth living” (Anderson, 2001, p. 145). The transactional opportunities of movement, including possibility, creativity, and freedom, provide possible "avenues for humanizing, for self-recovery and 'refreshment"' (p. 141). In other words, for Anderson (2001), the discovery of numerous possibilities and potential through sport creates a meaningful life and allows one to "become fully human" (p. 145).

Following Anderson, Hochstetler and Hopsicker (2012) argue that sport has the possibility to be humanizing and has "the potential for sustaining meaning and significance" (p. 119). For them, athletes (especially in endurance cycling and running) dedicate themselves to skill development and seeking and 
meeting challenges. Through this, they have "the opportunity to experience freedom and human agency" (Hochstetler \& Hopsicker, 2012, p. 122). For Hochstetler and Hopsicker (2012), endurance sport provides opportunities for growth and "human flourishing" (pp. 124, 132). Along with Anderson, Hochstetler and Hopsicker maintain that movement and sport are activities that allow humans to recognize their full potential and discover a wealth of possibilities.

The power of human flourishing can be found not only through challenge, but also by partaking in risky, dangerous sport. Howe (2008) and Russell (2005) argue that dangerous sport expands selfknowledge. For Howe (2008), "remote sports,"-those sports where athletes are separated by distance, from typical sport structures, and from quick emergency response and escape-provide the "opportunity for heightened testing of one's ability and character, and ultimately an affirmation of one's self" (p. 7). Through remote sport, athletes can find their limits of human potentiality. Russell (2005), similar to Howe, argues that dangerous sport provides a unique opportunity for the development of personal knowledge and satisfaction. Russell (2005) claims, that "participating in dangerous sport [...] can incorporate a challenge to capacities for judgment and choice that involves all of ourselves-our body, will, emotions, and ingenuityunder conditions of physical duress and danger at the limits of our being" (p. 14, emphasis original). Like Howe, Russell sees the risk inherent to dangerous sport as bringing about further knowledge of human limits and potential. Dangerous and remote sport can bring about a greater understanding of the self and of what it means to be human.

Although children may not take on certain risks, due to age and development, they may still find meaning from dangerous sport. In fact, Russell (2007) argues that because of the "physical danger" some sports "have special value because they challenge us to push the boundaries of who we are by extending in certain ways the physical, emotional, and intellectual limits of our finite, embodied selves," and that young participants benefit from partaking in some level of risk (p. 181). Participation in dangerous activities can help children develop the appropriate skills for adulthood and develop virtues, such as a mean of physical courage between foolhardiness and cowardice (Russell, 2007, p. 179).

Anderson, Hochstetler and Hopsicker, Howe, and Russell all illuminate the possibility that sport opens up the opportunity to understand and increase human potential. Importantly, all of them draw primarily from testing elements of sport, not sporting contests. It is the worthy test that allows athletes to search for their embodied limits, gain knowledge about their skills and humanity, and develop creative and free movements. These test-related journeys provide worthy alternate values for competitive athletes. Though these meanings and values are not necessarily divorced from competitive objectives, pursuing the limits of human potential can actively engage athletes and influence their performance. Attempting movements out of creativity, an increased sense of freedom, or just to see if one can accomplish the task, allows for sportspeople to transcend the values of winning and losing. Instead, athletes can develop a sense of meaning and understanding of the self through movement, regardless of the outcome, or even the presence, of a contest.

\section{Meaning through aesthetic value}

In addition to gaining meaningful experiences in sport through challenge and risk, some sportspeople recognize the importance of aesthetic value. This value is not incompatible with a level of competition, in fact, attempting to win and attaining a certain level of mastery are often key elements for beautiful and dramatic sport. However, as an alternate value, aesthetics can supersede the attention placed on winning. In this section, I will demonstrate two ways that aesthetics can serve as a significant source of meaning: (1) by developing an appreciation for graceful, beautiful, and artful movement and (2) by recognizing the dramatic elements of a sport contest.

In an attempt to draw meaning from aesthetic, athletic movements, some sport philosophers claim that sport is artful. Boxill (1984) argues that "a wellplayed game that is aesthetically pleasing is often the primary aim and is preferred to winning 'at all costs"' (p. 41). However, the artful athlete must be one who focuses on the development of her skills. For Boxill, the well-played game is both beautiful and skillful. She claims, "A performance or work cannot be beautiful unless the basics are mastered" (Boxill, 1984, p. 46).

Accordingly, aesthetic qualities are present within athletics. A beautiful jump shot or perfect pass can be as aesthetically pleasing and as valuable as a stunning painting or striking photograph. The grace and beauty associated with sport is imbued with greater significancethanjust denotations of skillfulmovement. Cordner (2003) asserts that graceful movement is contextualized by the skill in the movement form and indicates a comfort and confidence in oneself. We are attracted to the beautiful movements of a weightlifter 
(or any other athlete) because they provide a sort of meaning about the world, even if we do not enjoy weightlifting (or another sport) itself (Cordner, 2003, p. 139). In addition to admiring beautiful movements within the context of specific sports, we can also see the aesthetic nature of movement as part of a deeply human search for meaning. Elcombe (2012) argues that sport appeals to us as an embodied social practice that has the "ability to deepen the meaningfulness of our experience, to engage us fully and illuminate our embodied possibilities and limitations" (p. 214). On this analysis, aesthetics provide value to sport by enhancing, creating, and promoting meaningful experiences.

This view of sport as aesthetically meaningful is rooted in the value of athletic tests. The physical test involved in sport allows athletes to develop skillful, yet beautiful and graceful movements. Athletes can gain broader meanings through the aesthetic qualities of sport movements regardless of whether or not they won. They need not excessively focus on contesting elements of sport to find deep meaning and value.

Contesting also provides a resource for aesthetic value. Dramatic tension, arising, in part, from the unknown outcome of competition, can also serve as a viable alternate value in sport ${ }^{3}$. Drama and tension are abundantly present in athletic games (Kaelin, 1979, p. 329). Buckley (2006) notes that sport involves dramatic elements similar to those found in theater: athletes are united by rules as actors are united by a script; sports and plays resemble and instruct "life issues" such as morality; and both theater and sport require a level of uncertainty (pp. 25-28). Competitive games always have drama-even if it is not the drama the athletes hope for (for example, Buckley notes that Mallory and Irvine's ill-fated climb of Mount Everest was dramatic, though tragic, as they both died during their attempt) (Buckley, 2006, p. 33). For Kaelin (1979), the dramatic elements of sport ought to take a prominent place in the athletic practice. He hopes that coaches will put their reputations on the line by "going for the well-played game," where athletes might make risky plays that increase drama and tension, even if they ultimately cause the team to lose (p. 331). Kaelin and Buckley indicate the importance of drama to sport and aesthetics. Instead of relentlessly pursuing mere

3 To be sure, dramatic tension can develop from testing abilities. Meeting the challenge of the test may be so difficult that the question of whether or not the athlete completes it is dramatic. For example, the daredevil Nik Wallenda walked on a tightrope across both Niagara Falls and the Grand Canyon. While he did not meet any contesting challenges, the uncertainty of his ability to safely complete these feats was the source of dramatic tension. victory, according to Buckley and Kaelin, coaches and athletes can embrace the uncertainty of sport and even attempt to build dramatic tension in order to pursue aesthetic value.

These alternate sources of meaning in sport, including symbolism, challenge and risk, and aesthetics, are not exhaustive. A number of additional values can be found in high quality sporting experiences. However, these sites for alternate meaning illustrate the fact that sportspeople can find numerous reasons for participating in competitive sport. Embracing these as worthwhile at all levels of sport, especially youth sport, can communicate to young athletes that winning is not all that matters. Additionally, they can see that earning reward comes not just from participating, but from making faithful efforts to find and strive for symbolic meaning, challenge, and aesthetics.

\section{Expanding interpersonal relationships in sport}

Citizenship, sportsmanship, and teamwork are often cited by youth sport advocates as primary goals for young athletes. Thus, interpersonal relationships are an essential part of the youth sport projectincluding relationships with both opponents and teammates. Instead of seeing opponents as enemies, at worst, or facilitators, at best, athletes can see others as companions in the test and even as friends (Hyland, 1978). Furthermore, players who do not excessively focus on victory can see their teammates as more than mere instruments for winning or distractions from personal merit, but also as friends with shared values, trust, and loyalty.

\section{Relationships with opponents}

When athletes focus mainly on winning games, they often see opponents as obstacles to overcome or as an enemy. The other person or team stands in the way of their goal-namely, victory. According to Fraleigh (1984), when opponents are seen as obstacles, they stand between the athlete and his or her goal and are “"at once feared and needed"' (p. 84). In these cases, competition "requires me to eliminate the obstacle" (Fraleigh, 1984, p. 84). For Fraleigh (1984), this is problematic because the "other" is viewed negatively and as a means to achieving goals (p. 86). Demonizing the opponent as an enemy not only constitutes a moral wrong, but also limits the range of possibilities provided by the opponent. As enemies, competitors only serve as an obstacle to overcome. As facilitators, 
opponents not only provide an obstacle, but also help to create the contest and motivate their counterpart toward success. In short, opponents need not and should not be seen as enemies.

Fraleigh argues that through mutual cooperation, opponents facilitate the competition. In this vein, seeing opponents as facilitators allows for a level of respect to develop and for opponents to be both a means and an end (Fraleigh, 1984, p. 86). According to Fraleigh, seeing the opponent as a facilitator is "for the good of everyone alike" for a number of reasons. First, the hindrance provided by the opponent is maintained as the "hindrance for the mutual pursuit of the goal." Secondly, excellence still occurs and is likely contingent upon seeing athletes as facilitators. Without an opponent playing good defense, the athlete cannot fully show his or her offensive moves. Third, both competitors can attempt to achieve their best when they see each other as facilitators. Fourth, seeing the opponent as a facilitator promotes "sweet tension." And, finally, this viewpoint "helps make the sports contest a human event wherein the mutual respect and regard of opponents is evident" (Fraleigh, 1984, pp. 89-91).

In contests, opponents also serve as an important motivator. Though not necessarily through overt means (i.e. giving instructions to improve swing to one another), opponents can tacitly inspire stronger performances from one another. By playing against a reasonably talented opponent, especially one matched in skill level, athletes may reach higher potential excellence than in non-competitive scenarios. Better contests occur because of the presence and motivation of another player. Athletes may hit a golf ball better or run faster when they are attempting to do it better than someone else.

On these descriptions of opponents as facilitators, competitors are viewed as a means to an end, as instrumentally valuable. However, relationships between opponents can take on a deeper meaning and move toward recognizing competitive others as human, not at instruments but as ends in themselves. One way these deeper relationships occur is through empathy. There is something unique about sport that, with its shared struggles and difficulties, makes it a prime source of deep and intimate relationships. Watching others grapple with similar problems as oneself can invite empathy among opponents. Opponents can also appreciate the other's skills, talents, and difficulties inherent in striving toward excellence. Sharing a similar struggle to develop and improve the contesting and testing skills necessary for success in a sport can build bonds. These relationships may deepen when opponents meet often, forming closer ties by watching each other play frequently and by responding to the skills and strategies of their opponents regularly. Through empathy and shared striving, opponents can recognize each other at a human level, as more than a means, as people who face the same difficulties, celebrate similar achievements, and relish comparable joys.

Hyland (1978) takes the opponent relationship to another level, arguing that competition can inspire friendship. For him, competition and friendship have a teleological relationship where "the highest version of competition is as friendship" (Hyland, 1978, p. 35). He even goes as far as to make a normative claim: "we ought to strive at all times to let our competitive play be a mode of friendship" (Hyland, 1978, p. 35, emphasis original). He suggests that we should see our competitors as something more than merely a facilitator. Opponents do not only serve to aid in creating the test and the contest-they form relational bonds by participating in the same project. For Hyland (1978), competition is a "mutual striving" where "it is a questioning of each other together, a striving together" (p. 34, emphasis original).

Hyland is not the only one to see competition as a mutual striving. Simon (2010) defines lusory competition as a "mutual quest for excellence through challenge" (p. 27). For Simon and Hyland, the other is a necessary part of the contest. Without this cooperation, the competition would not exist. But, the opponent does not exist merely to create the contest. Instead, the togetherness and mutuality inspired by competition allow both opponents to strive to new excellences perhaps unattainable without the other. Opponents can push each other to their limits so that they can achieve the highest levels of excellence possible to them. In short, the mutuality and friendship associated with competition makes not only for better contests, but for better players.

Opponents can also enter relationships based on mutuality and respect. According to Kretchmar (1975b), following Buber's discussion of the "I-Thou" relationship, "Frequently a kind of fraternity among opponents in a single sport develops" (p. 23). Opponents share a test and share in attempting to overcome the obstacles of the test. For example, basketball players share in their attempts to put a ball through a hoop. Though they actively attempt to prevent the other from that goal, these basketball players maintain a relationship that relies on a mutual understanding of the rules and goals of the game. This illustrates Kretchmar's (1975b) point that "A common 'adversary' is identified as the conditions 
of the test and not only as fellow athletes...A problem is shared" (p. 23). For Kretchmar, this relationship among opponents challenges the nature of a successful sport contest. Instead of counting victory as the only means to assess the success of a contest, the mutuality and dialogue shared by opponents produces a profoundly human interaction (Kretchmar, 1975b, p. 27).

These analyses indicate that mutuality and friendship should reign supreme in opponent relationships. This occurs through acting as facilitators and as friends. It inspires both good contests and respect for others as persons. This new focus allows for the recognition of testing families-where players in the same sport identify with one another and hold similar values. Soccer players, whether they are teammates or opponents, hold similar beliefs and goals and share an understanding of the game. Testing families draw ties across competition and help improve relationships among players.

For participants in youth sport, the opportunity to build friendships and ties within a testing family offers important value. Youngsters who develop these strong relationships with others can begin on a path toward long-term participation in the sport, which meets the goals of many youth athletics organizations. Organizers, coaches, and parents ought to encourage these friendships. Thus, developing strong relationships with opponents serves as a potential site for rewarding youth athletes.

\section{Relationships with teammates}

In some ways, issues surrounding relationships with teammates involve similar problems as those found in relationships with opponents ${ }^{4}$. Seeing teammates as instruments for individual success poses the same problems as seeing opponents merely as facilitators. Though they are necessary to create the contest, seeing them as facilitators, in some ways, relegates them to a merely instrumental status, just as it does when dealing with opponents. However, relationships with teammates necessarily include open communication and trust in order to be successful in sport (Shogan, 1999, p. 81). A lack of respect toward persons does not manifest as deeply when dealing with teammates, as their success is often shared with the team. Furthermore, developing friendships with teammates seems more natural and is often a result of continual mutual cooperation.

\footnotetext{
4 Because teammates are not present in individual sports, these remarks may not be widely applicable beyond team sports.
}

On the other hand, teammate relationships face unique challenges. Bellah, Madsen, Sullivan, Swindler, and Tipton (2008) argue that individualism has permeated Western culture and creates a number of problems. When individualism carries into sport, it can manifest as the specific player putting his or her needs above those of the rest of the team. For those that act this way, personal ambitions trump team goals and the success of the person is more important than the success of the entire team. Believing that one's own goals hold a higher importance than those of others and of the team demonstrates a level of selfishness that allows an athlete to see his or her teammates as instrumental-as merely a means to an end. Without their teammates, athletes might not be able to accomplish these goals, but they do not demonstrate their appreciation through respecting them as persons.

Eliminating this individualism, at least to some extent, can help relieve the problems associated with placing the self above others. Therefore, a greater emphasis can be placed on the goals of the team, on respect for others, and loyalty toward teammates. Instead of narrowly focusing on the self, mitigating individualist attitudes can help to remove the overemphasis on personal goals and renew the emphasis on the team.

Gréhaigne's (2011) analysis of collective sport additionally follows an elimination of excessive individualism from athletics. Following the work of Sartre, Gréhaigne (2011) argues that a team relies on a differentiation of function among team members ( $p$. 37). Team members cannot all perform the same tasks; they must take on complementary roles in order to function well. Thus, teams are cohesive groups with a sort of unity. They are tied together not only by shared experiences, but because members take a "vow" which allows the group to "assert itself as permanent, and therefore objectivizes itself" (Gréhaigne, 2011, p. 41). Therefore, teammates not only share past experiences of overcoming challenges and obstacles, but are united it efforts to continue to work together in attempts to tackle new objectives. Teammates rely on one another, as they have differentiated their skills and functions, to achieve their goals. Thus, relationships among teammates must be based on strong, committed relationships with one another.

Just as young athletes can find value in developing strong relationships with opponents, they too can form close ties to teammates. Because the focus is on the common ground of the testing family and on the fact that athletes enjoy mutual benefits by treating each other humanely, they can develop richer and 
deeper relationships. Rewarding young participants for growing connections to others falls in line with the goal of youth sport. It helps them develop bonds with others and learn to become part of a larger sporting community. Placing value on these relationships, both with teammates and opponents, can signal to children playing sport that treating others with respect, loyalty, and mutuality deserves just reward.

\section{Rewarding youth sport participants for discovering alternate values}

I have argued that sport provides alternate values for participants, beyond the standard goal of winning. The question remains, however, of whether and how to reward players for attaining, or striving to attain, these values. Unlike victory, it is more difficult to assess whether a young athlete has discovered new meaning through challenge, risk, or aesthetics or if they have gained a new appreciation of their teammates or opponents. In addition to the difficulty in assessing these values, coaches may also feel wary of handing out any awards. The National Alliance for Youth Sports (NAYS) does not even suggest awarding young athletes for victory. Though they permit keeping score and tournament play for athletes 9 years of age and older, they suggest that it not be emphasized. Thus, coaches and youth sport organizations attempting to follow the policies put forth by NAYS would be unlikely to offer championship trophies or hold playoff tournaments to determine and reward a victorious team. However, most children and coaches do keep score and are aware of the external good associated with winning.

An excessive focus on external goods may lead to other problems for young athletes. If they are only motivated by external factors (such as receiving a trophy), internal goods may suffer. For example, Howes (2016) argues that too much focus external goods (such as fitness and health) may undermine other internal goods of sport (p. 133). While external goods can be worthwhile pursuits, sport participants should not "overvalue [...] them to the extent that we weaken our ability to attain the internal goods of practices" (Howes, 2016, p. 134). Additionally, social science research suggests that extrinsic and intrinsic motivation can conflict with one another and that over time, those external rewards do little to generate longlasting interest in a task (Bénabou \& Tirole, 2003, p. 490). External rewards, if distributed excessively to young athletes, may negatively affect the sportsperson's ability to attain or strive for internal goods, such as meaningful movement. Rewarding players with large trophies, like those given to James Harrison's children, may prove to have adverse impact on the goals of youth sport. Instead of teaching and training young athletes in a particular set of sport skills and helping them develop a long, and potentially lifelong, relationship with athletics, trophies may promote external reward systems that ultimately don't pay off.

While concerns about extrinsic rewards undermining intrinsic motivation are valid, some research indicates that it may be possible to have both. Lemos and Veríssimo (2014) demonstrate that intrinsic and extrinsic motivation can operate separately. Their study of elementary school children showed that classroom achievement can be caused by both intrinsic and extrinsic motivation (Lemos \& Veríssimo, 2014, p. 935). Furthermore, Lepper, Henderlong Corpus, and Iyengar (2005) found that students can exhibit both intrinsic and extrinsic motivation in the classroom ( $p$. 190). Therefore, it is not necessarily true that external reward systems will always undermine intrinsic motivation. While intrinsic motivation remains more positive and correlated with better achievement and performance (Lepper et al., 2005, p. 192), the fact that they can co-exist may open possibilities for offering some external rewards while simultaneously encouraging intrinsic motivation.

External goods also, to a degree, indicate social values. If only winners receive rewards, then the message is clear: what matters most is winning. Reactions to Harrison's post on social media included comments on Facebook, such as "Epic parenting win" and "Sadly, we now live in the 'trophy generation.' Proud of him for taking a stand" (Dator, 2015). What these commenters, and others who agreed with the sentiment, including a number of sportswriters, mean is that the only way to really "earn" a trophy is to win. By emphasizing this, along with disparaging external rewards associated with other things, such as participation, these opponents to participation trophies send a strong message. Victory matters and other outcomes and goods do not.

Based on the need to emphasize a variety of values in youth sport, along with concerns about intrinsic and extrinsic motivation, I suggest that young sport participants should be rewarded with small tokens for a variety of achievements and value attainment. These tokens of achievement may include t-shirts, small medals, ribbons, or other meaningful items. Large trophies, like those from Harrison's Instagram photograph, should generally be avoided in order to quell concerns about external rewards. Additionally, these tokens should be given for more than just 
victory. By rewarding all (or at least many) of the players, even if they lost, youth sport organizations and coaches signal to the young athletes that striving for other values, such as personal meaning, aesthetics, challenge, risk, and interpersonal relationships, is worthwhile. Coaches may determine different ways of distributing these types of awards, such as giving them to different players at regular intervals throughout the season or giving a variety of awards at the end of the season.

The message remains in either of these scenariosachieving and striving for a variety of values, including, but not limited merely to victory, is worthwhile and meaningful.

\section{REFERENCES}

About Pop Warner Youth Football, Cheer \& Dance. (n.d.). Retrieved October 30, 2017, from https://tshq.bluesombrero.com/Default. aspx?tabid=1403206

Anderson, D. (2001). Recovering humanity: Movement, sport, and nature. Journal of the Philosophy of Sport, 28(2), 140-150. https://doi. org/10.1080/00948705.2001.9714609

Bellah, R. N., Madsen, R., Sullivan, W. M., Swidler, A., \& Tipton, S. M. (2008). Habits of the heart: Individualism and commitment in American life (3rd ed.). Berkeley and Los Angeles: University of California Press.

Bénabou, R., \& Tirole, J. (2003). Intrinsic and extrinsic motivation. The Review of Economic Studies, 70(3), 489-520.

Bostick, D. (2015, August 18). The real story about the participation trophies Pittsburgh Steelers LB James Harrison returned. Retrieved from https://www.huffingtonpost.com/dani-bostick/the-real-storyabout-the-participation-trophies_b_8006122.html

Boxill, J. M. (1984). Beauty, sport, and gender. Journal of the Philosophy of Sport, 11(1), 36-47. https://doi.org/10.1080/00948705.1984.9714413

Buckley, A. D. (2006). Aristotle and cricket: Drama in retrospect. Journal of the Philosophy of Sport, 33(1), 21-36. https://doi.org/10.1080/009 48705.2006.9714688

Cordner, C. (2003). The meaning of graceful movement. Journal of the Philosophy of Sport, 30(2), 132-143. https://doi.org/10.1080/00948 705.2003.9714639

Dator, J. (2015, August15). James Harrison tookawayhiskids' participation trophies because they didn't "earn" them. Retrieved October 30, 2017, from https:/www.sbnation.com/lookit/2015/8/15/9160799/jamesharrison-kids-participation-trophies-facebook-steelers-nfl

Elcombe, T. L. (2012). Sport, aesthetic experience, and art as the ideal embodied metaphor. Journal of the Philosophy of Sport, 39(2), 201217. https://doi.org/10.1080/00948705.2012.725901

Fraleigh, W. P. (1984). Right actions in sport: Ethics for contestants. Champaign, IL: Human Kinetics.

Grehaigne, J. F. (2011). Jean-Paul Sartre and team dynamics in collective sport. Sport, Ethics and Philosophy, 5(1), 34-45.

Hochstetler, D., \& Hopsicker, P. M. (2012). The heights of humanity: Endurance sport and the strenuous mood. Journal of the Philosophy of Sport, 39(1), 117-135. https://doi.org/10.1080/00948705.2012.6 75067

Howe, L. A. (2008). Remote sport: Risk and self-Knowledge in wilder spaces. Journal of the Philosophy of Sport, 35(1), 1-16. https://doi.org/ 10.1080/00948705.2008.9714724

Howes, M. (2016). Challenging fitness ideology: Why an adventurous approach to physical activity is better for well-being. Sport, Ethics and Philosophy, 10(2), 132-147.

Hyland, D. A. (1978). Competition and friendship. Journal of the Philosophy of Sport, 5, 27-37.
Jennings, C. (2014, June 11). Sharika Nelvis leaps life's hurdles. Retrieved June 10, 2015, from http://espn.go.com/espnw/news-commentary/ article/11060250/espnw-arkansas-state-track-star-sharika-nelvisovercoming-life-hurdles

Kaelin, E. F. (1979). The well-played game: Notes toward an aesthetics of sport. In E. W. Gerber \& W. J. Morgan (Eds.), Sport and the Body: A Philosophical Symposium (2nd ed.). Philadelphia: Lea \& Febiger.

Kretchmar, R. S. (1975a). From test to contest: An analysis of two kinds of counterpoint in sport. Journal of the Philosophy of Sport, 2(1), $23-$ 30. https://doi.org/10.1080/00948705.1975.10654094

Kretchmar, R. S. (1975b). Meeting the opposition: Buber's "will” and "grace" in sport. Quest, 24(1), 19-27.

Lemos, M. S., \& Veríssimo, L. (2014). The relationship between intrinsic motivation, extrinsic motivation, and achievement, along elementary school. Procedia-Social and Behavioral Science, 112, 930-938.

Lepper, M. R., Henderlong Corpus, J., \& Iyengar, S. S. (2005). Intrinsic and extrinsic motivational orienations in the classroom: Age differences and academic correlates. Journal of Educational Psychology, 97(2), 184-196.

MacIntyre, A. (1984). After virtue: A study in moral theory (2nd ed.). Notre Dame, IN: University of Notre Dame Press.

Metheny, E. (1965). Connotations of movement in sport and dance: A collection of speeches about sport and dance as significant forms of human behavior. Dubuque, IA: Wm. C. Brown Company Publishers.

Mission \& Vision. (n.d.). Retrieved October 30, 2017, from http://www. ayso.org/aboutayso/mission.htm\#.WfetdVtSyUk

National Alliance for Youth Sports. (2017). National Standards for Youth Sports.

Reilly, R. (2014, June 10). Heading for home. Retrieved June 11, 2014, from http://espn.go.com/espn/story/_/id/11049946/rick-reilly-lastcolumn

Russell, J. S. (2005). The value of dangerous sport. Journal of the Philosophy of Sport, 32(1), 1-19. https://doi.org/10.1080/00948705 2005.9714667

Russell, J. S. (2007). Children and dangerous sport and recreation. Journal of the Philosophy of Sport, 34(2), 176-193.

Shogan, D. (1999). The making of high-performance athletes: Discipline, diversity, and ethics. Toronto, ON, Canada: University of Toronto Press.

Simon, R. L. (2010). Fair play: The ethics of sport (3rd ed.). Boulder, CO Westview Press.

Torres, C. R., \& Hager, P. F. (2007). De-emphasizing competition in organized youth sport: Misdirected reforms and misled children. Journal of the Philosophy of Sport, 34(2), 194-210.

Why We Are Relevant. (n.d.). Retrieved October 30, 2017, from http:// www.littleleague.org/Little_League_Big_Legacy/About_Little_ League/Why_We_Are_Relevant.htm 